\title{
ANÁLISE DO ESTADO DE COISAS INCONSTITUCIONAL NA ADPF 347 E SEU PAPEL COMO INSTRUMENTO NA EFETIVAÇÃO DA POLÍTICA PÚBLICA CARCERÁRIA
}

\author{
Amanda Nunes Lopes Espiñeira Lemos ${ }^{1}$ \\ Gabriel Dias Marques da Cruz $^{2}$
}

\section{RESUMO:}

Este trabalho objetiva perceber os desdobramentos da incorporação da técnica colombiana do "estado de coisas inconstitucional" pelo Supremo Tribunal Federal na jurisdição brasileira, por meio da Arguição de Descumprimento de Preceito Fundamental no 347. Assim, propõe-se a analisar a ADPF 347 como instrumento de efetividade da política pública prisional, objeto da ação. A partir do modelo do "policy cycle", busca-se compreender em qual etapa desse ciclo da política pública carcerária a ADPF se insere e quais as repercussões da incorporação do ECI pelo STF nesta ação, para sua efetivação. Trata-se de um estudo de caso da ADPF 347, em uma análise qualitativa, por meio de pesquisa bibliográfica e jurisprudencial.

Palavras-chave: controle de constitucionalidade; estado de coisas inconstitucional; ADPF 347; natureza jurídica; ciclo das políticas públicas.

\section{ANALYSIS OF THE UNCONSTITUTIONAL STATE OF AFFAIRS IN ADPF 347 AND ITS ROLE AS AN INSTRUMENT IN THE EFFECTIVENESS OF CARCERARY PUBLIC POLICY}

\begin{abstract}
:
This paper aims to see how this context can be considered an "unconstitutional state of affairs" and how the Brazilian Supreme Court in ADPF 347 incorporate that. Thus, this research proposes to analyze the ADPF 347, leaning on its role as an instrument of effectiveness of the prison public policy, object of the lawsuit. Under the perspective of the policy cycle, the paper aims to understand at what stage of the cycle the complaint for non-compliance of fundamental precept falls. It is a case study of ADPF 347, in a qualitative analysis, through bibliographical and jurisprudential researches.
\end{abstract}

Keywords: judicial review; ADPF 347; unconstitutional state of affairs; legal nature; policy cycle.

\footnotetext{
${ }^{1}$ Mestranda em Direito pela Universidade de Brasília (UnB). Advogada. Bacharela em Direito pela Universidade Federal da Bahia (UFBA). Membro dos grupos de pesquisa Observatório de Políticas Públicas (GEOPP) na UnB e Controle de Constitucionalidade (GPCC) na UFBA. amandaespineira@gmail.com.

${ }^{2}$ Mestre e Doutor em Direito do Estado pela Universidade de São Paulo (USP). Professor Adjunto de Direito Constitucional - UFBA e Faculdade Baiana de Direito. gabriel_dmc@yahoo.com.br.
} 


\section{INTRODUÇÃO}

A Arguição de Descumprimento de Preceito Fundamental $n^{\circ} 347$ foi ajuizada considerando-se a situação degradante das penitenciárias no Brasil, a fim de garantir a integridade física e moral dos custodiados. Propôs-se a ação perante o Supremo Tribunal Federal em face das violações massivas dos direitos fundamentais nas prisões do país, que decorrem de ações e omissões dos Poderes Públicos da União, dos Estados e do Distrito Federal, envolvendo-se os Poderes Executivo, Legislativo e Judiciário. Assim, requereu-se, em sede de cautelar, que o sistema penitenciário nacional fosse caracterizado como um "estado de coisas inconstitucional" (ECI).

Os problemas de pesquisa desta investigação são: como o STF incorporou o "estado de coisas inconstitucional" na ADPF 347 ao sistema jurídico brasileiro? Em qual ciclo da política carcerária a propositura da ação se insere, como e em que ela interfere na sua efetivação? Buscase, dessa forma, compreender, sobretudo a partir do acórdão liminar da ação, as repercussões da ação em si na política pública do sistema prisional, por meio dos seus ciclos, diante da relevância constitucional e social que esse levantamento poderá proporcionar.

Dessa forma, o objetivo deste trabalho é analisar o ECI na ADPF 347 e sua repercussão na efetivação da política pública carcerária, objeto da ação, a partir da classificação do "ciclo das políticas públicas". Para tanto, cumpre-se os seguintes objetivos específicos: apresentar breve contextualização do sistema carcerário brasileiro; sistematizar em análise comparativa os argumentos utilizados pelos Ministros nos seus votos no Acórdão liminar da ADPF 347; observar a conexão entre a política pública carcerária, objeto da ADPF, com a própria ação; compreender de que forma o conceito colombiano do estado das coisas inconstitucional se relaciona com a ADPF 347 enquanto instrumento da efetivação da política pública objeto da ação, dentro do controle de constitucionalidade brasileiro; verificar os estágios do ciclo das políticas públicas em uma revisão bibliográfica sobre o tema; identificar em qual ciclo da política a propositura da ação se insere, como e em que ela interfere na sua efetivação.

Diante do objetivo proposto, utiliza-se com referencial teórico o ciclo das políticas públicas, que constitui um esquema interpretativo derivado da teoria dos sistemas e organiza uma política pública em etapas sequenciais e interdependentes. Não obstante a importância didática desse conceito, inclusive para sistematização e compreensão da política, sua dinâmica na prática apresenta as fases misturadas e alternadas. O modelo pode ser sintetizado em sete fases principais: a identificação do problema, a formação da agenda, a formulação de alternativas, a tomada de decisões, a implementação, a avaliação e a extinção. A partir dessa 
teoria, objetiva-se perceber em qual etapa desse ciclo se insere a judicialização da política pública carcerária por meio da ADPF 347. Verificar o contexto da elaboração da política pública criminal e penitenciária auxilia no entendimento das deficiências deste, bem como no aprimoramento e criação de outros instrumentos. Compreende-se, então, a ADPF como um instrumento do controle de constitucionalidade concentrado importante para evitar violações de direitos humanos no sistema prisional brasileiro.

Metodologicamente trata-se de uma análise qualitativa. $\mathrm{O}$ processo desta pesquisa foi composto por duas etapas basilares que compõe essa espécie metodológica: (1) fase exploratória e (2) análise e tratamento do material empírico e documental (MINAYO, 2007). Então, a partir da pesquisa bibliográfica e jurisprudencial, realiza-se um estudo de caso da ADPF 347, com o objetivo de conhecer a sua decisão em profundidade sob a perspectiva da política pública impugnada pela ação no processo decisório do controle de constitucionalidade. A hipótese da pesquisa é que a $\operatorname{ADPF} 347$, cujo objeto é a política carcerária brasileira, ao almejar o reconhecimento do ECI, se insere na etapa do ciclo das políticas públicas conhecida como avaliação, não obstante as etapas também dialogarem, o que possibilita que as diretrizes pleiteadas na arguição se insiram na etapa da "formulação de alternativas".

O trabalho, diante dos elementos até aqui expostos, é composto por três partes. A primeira possui uma breve contextualização da ADPF 347 e da situação da política carcerária nacional. Na segunda se realiza a análise da decisão liminar, em que se extrai de forma elucidativa os argumentos centrais da Ementa do Acórdão e aqueles utilizados nos votos dos Ministros em uma análise comparativa. A terceira inicia-se com uma breve introdução ao "policy cycle", após explanar as fases do ciclo, analisa-se em qual dessas etapas a ADPF 347 se insere na política carcerária. E por fim, demonstram-se as repercussões na efetivação da política pública carcerária do ECI na ADPF 347.

\section{BREVE CONTEXTUALIZAÇÃO DA ADPF 347 E DA POLÍTICA CARCERÁRIA E PRISIONAL}

A ADPF $n^{\circ} 347$, objeto da análise deste trabalho, foi ajuizada, em maio de 2015, pelo Partido Socialismo e Liberdade (PSOL), representado pelo advogado constitucionalista Daniel Sarmento, cuja petição inicial se baseia em representação formulada pela Clínica de Direitos Fundamentais da Faculdade de Direito da UERJ, fundamentada em parecer do Professor de Direito Penal da instituição, Juarez Tavares. A ação, que tem como réus a União e todos os vinte e seis estados da federação e o Distrito Federal, foi proposta objetivando sanar as gravíssimas lesões a preceitos fundamentais da Constituição, ante o quadro de violação massiva 
e persistente de direitos fundamentais decorrentes de condutas comissivas e omissivas dos poderes públicos no tratamento da questão prisional do país. Requereu-se, então, em medida cautelar, o reconhecimento do ECI do sistema penitenciário brasileiro. O plano de fundo da ação é o cenário bastante desumano das prisões brasileiras, com celas superlotadas, insalubres, proliferação de doenças infectocontagiosas, comida de baixa qualidade, falta de água potável e de produtos higiênicos básicos. Homicídios, espancamentos, tortura e violência sexual contra os presos são frequentes, praticadas por outros detentos ou por agentes do próprio Estado.

A afronta da vexaminosa realidade dos nossos cárceres aos princípios e garantias constitucionais, assegurados pela CRFB/88, à dignidade da pessoa humana (art. $1^{\circ}$, III); à proibição da tortura e do tratamento desumano ou degradante (art. $5^{\circ}$, III); à vedação as sanções cruéis (art. $5^{\circ}$, XLVII, “e”); à garantia do cumprimento da pena em estabelecimentos distintos, de acordo com a natureza do delito, a idade e sexo do apenado (art. $5^{\circ}$, XLVIII); ao respeito à integridade física e moral dos presos (art. $5^{\circ}$, XLIX); à presunção de inocência (art. $5^{\circ}$, LVII) e a outros inúmeros direitos fundamentais como saúde, educação, alimentação adequada e acesso à justiça, somada à incompatibilidade da situação prisional com diversos tratados internacionais sobre direitos humanos ratificados pelo Brasil, como o Pacto dos Direitos Civis e Políticos, a Convenção contra a Tortura e outros Tratamentos e Penas Cruéis, Desumanos e Degradantes e a Convenção Interamericana de Direitos Humanos são utilizados como argumentos pelo PSOL para justificar a necessidade da ADPF e a intervenção do Judiciário na questão. Ademais, o ambiente das prisões superlotadas frustra o objetivo de ressocialização da pena, e contribui para a instauração de um ambiente violento nas instituições prisionais.

A exordial foi instruída com diversos documentos utilizados como dados e subsídio também para esse trabalho, a exemplo do Relatório da Comissão Parlamentar de Inquérito (CPI) do sistema carcerário. Esta CPI teve por objetivo investigar a realidade do Sistema Carcerário Brasileiro e buscar soluções para o efetivo cumprimento da LEP. O seu relatório final publicado em 2009 apresenta dados que embora um pouco já defasados, uma vez que foi realizada em 2007 e 2008, ainda refletem exatamente a realidade e o cenário do sistema carcerário brasileiro, questão fática motivadora do ajuizamento da ADPF 347. O documento ressalta que "apesar da excelente legislação, os presos no Brasil, em sua esmagadora maioria, recebem tratamento pior do que o concedido aos animais: como lixo humano ". (BRASIL, 2009, p.172).

Tal estado calamitoso do nosso sistema penitenciário é reconhecido também no STF, em ações anteriores. Este fato, diante da gravidade das violações aos direitos humanos dos presos, motivou intervenções da Corte Interamericana de Direitos Humanos, que condenou o 
Estado brasileiro a cumprir medidas provisórias para garantir a erradicação das situações de risco e providenciar a proteção à vida e à integridade pessoal, psíquica e moral de pessoas privadas de liberdade em várias penitenciárias do país. A Comissão Interamericana de Direitos Humanos (2011) dialoga com o parecer acima transcrito da CPI (2009, p.172) ao afirmar que "quando os cárceres não recebem a atenção e os recursos necessários, a sua função se distorce e, em vez de proporcionarem proteção, se convertem em escolas da delinquência e comportamento antissocial, que propiciam a reincidência em vez da reabilitação" (p.4-5).

Diante desse contexto, o Conselho Nacional de Política Criminal e Penitenciária (CNPCP) do Ministério da Justiça traçou um Plano da Política Criminal e Penitenciária, trazendo alternativas para o sistema carcerário, que tinha por objetivo de criar 45.934 vagas novas em todo o país até o final de 2014, para reduzir a superlotação. A União celebrou convênios com os estados visando à realização de 99 obras. Destas, consta que 46 nem começaram, 33 estão paralisadas e só 20 estão em andamento, ainda que com grande atraso (BRASIL, 2015, p.30). De igual modo esses elementos acima são apresentados pelo Conselho Nacional do Ministério Público (CNMP, 2013), cujo relatório traça o perfil da população carcerária e das características dos presídios brasileiros em um levantamento por amostragem dos estabelecimentos inspecionados.

Antes dos demais documentos trabalhados acima, Adorno diagnostica exatamente os mesmos pontos problemáticos das prisões brasileiras, acima especificados. E na mesma ideia de melhor implementar as políticas públicas carcerárias, o autor diz que "somente na dimensão política que a questão penitenciária se clara", para tanto demonstra-se ser “indispensável, antes de tudo, conhecer a magnitude dos problemas com que se defronta (...) os elementos e fatores condicionantes de sua dinâmica, os interesses em jogo, as diferentes concepções que lhe são inerentes e que ganham peso em determinadas conjunturas" (ADORNO, 1999, p. 75-76).

Como se pode notar, a realidade do sistema carcerário brasileiro apresentou pouquíssimas mudanças desde 1999 até 2015, quando a ADPF 347 foi proposta. Na ação postula-se, em síntese, que a Corte reconheça e declare o ECI do sistema prisional brasileiro. A arguição, então, é voltada ao enfrentamento de violações graves e sistemáticas da Constituição, decorrentes de falhas estruturais em políticas públicas que envolvam um grande número de pessoas, e cuja superação demande providências variadas de diversas autoridades e poderes estatais. Ademais, da forma pela qual foi proposta a ADPF desafia a intervenção da jurisdição constitucional brasileira, não apenas aspectos do controle, mas outras ações ou omissões do poder público. Pugna-se pela proteção à dignidade de grupos vulneráveis, em um 
exercício do papel contramajoritário do STF. Diante do pedido em caráter liminar incorporouse o instrumento colombiano denominado ECI.

Essa técnica deve ser utilizada apenas em casos em que se identifica um "bloqueio institucional" para a garantia dos direitos, o que leva a Corte a assumir um papel atípico, sob a perspectiva do princípio da separação de poderes, que envolve uma intervenção mais ampla sobre o campo das políticas públicas. (ARIZA, 2013). Este mecanismo não se volta apenas ao controle de constitucionalidade de atos normativos, antes deve enfrentar também outras afrontas à Constituição, decorrentes de atos e omissões dos poderes públicos, especialmente quando se constate que estão em jogo os direitos mais básicos de uma minoria estigmatizada. Exige-se que estejam presentes as seguintes condições para que se declare o ECI: (a) vulnerabilidade massiva e generalizada de direitos fundamentais de um número significativo de pessoas; (b) prolongada omissão das autoridades no cumprimento de suas obrigações para garantia e promoção dos direitos; (c) a superação das violações de direitos pressuponha a adoção de medidas complexas por uma pluralidade de órgãos, envolvendo mudanças estruturais, que podem depender da alocação de recursos públicos, correção das políticas públicas existentes ou formulação de novas políticas, dentre outras medidas; e (d) potencialidade de congestionamento da justiça, se todos os que tiverem os seus direitos violados acorrerem individualmente ao Poder Judiciário. (CAMPOS, 2015, p.134-138).

A Corte Constitucional da Colômbia vem utilizando o ECI desde 1997, e já foi empregado em pelo menos nove casos, tendo um deles versado exatamente sobre o sistema prisional do país. Tratou-se do processo T-153 de 1998, em que se reconheceu o ECI daquele sistema penitenciário. A ação ajuizada buscava, a princípio, resolver os casos concretos das prisões Bellavista e Modelo, entretanto, a decisão se generalizou e acabou por abordar o sistema carcerário do país como um todo. Outra decisão importante em que a Corte Constitucional colombiana reconheceu o ECI foi relacionada ao problema dos "desplazados", que são cerca de três milhões de colombianos que foram forçados a se deslocar, em razão da guerrilha e da violência generalizada que atingiu várias regiões daquele país (SARAVIA; RODRÍGUEZ, 2015). Nessa decisão, introduziu-se uma novidade importante na técnica do ECI: a Corte, após impor inúmeras medidas a diversos órgãos e autoridades públicas, reteve a sua jurisdição, para monitorar a implementação das suas ordens. O monitoramento, além de assegurar uma maior eficácia da decisão, também conferiu maior legitimidade e transparência ao processo, por meio de amplo diálogo entre a Corte, os beneficiários da sentença, as autoridades demandadas e a sociedade civil colombiana. (HUAROTO, 2013; GRAVITO; FRANCO, 2010) 
A teoria do ECI não é estranha à jurisprudência do STF. O Ministro Barroso, no votovista que proferiu na Questão de Ordem suscitada nas Ações Diretas de Inconstitucionalidade $\mathrm{n}^{\circ} \mathrm{s} 4.357$ e 4.425, atinentes à modulação temporal da decisão que reconheceu inconstitucionalidades na Emenda Constitucional $\mathrm{n}^{\circ}$ 62, que tratara do pagamento de precatórios, aludiu ao "estado de inconstitucionalidade grave e permanente que se instaurou no país, em relação ao pagamento de condenações judiciais contra a Fazenda Pública". A Corte atribuiu ao $\mathrm{CNJ}$ a função de elaborar proposta normativa para equacionar os problemas, bem como o papel de monitorar e supervisionar o cumprimento das medidas que impusera aos entes públicos.

Dessa forma, cenários de grave e massiva violação de direitos, decorrentes de falhas estruturais em políticas públicas, que caracterizam o ECI, demandam muitas vezes soluções complexas dos tribunais, que não se afeiçoam à sua função tradicional, de invalidação de atos normativos. Nestas hipóteses, o papel de guardião da Constituição exige uma postura diferenciada, sob pena de frustração dos direitos fundamentais e inefetividade da Constituição.

A partir do contexto apresentado questiona-se: o ECI na ADPF 347 é utilizado como uma técnica decisória ou alcançada por ela para superá-la (como um estado temporário caótico)? Seria então uma espécie de ativismo judicial?

\section{SISTEMATIZAÇÃO DO ACORDÃO}

Esgotada a contextualização da ADPF 347 e da situação do sistema carcerário que é plano de fundo da ação, passa-se a analisar os argumentos dos votos do Acórdão que decidiu os pedidos liminares em sede cautelar, a fim de perceber a utilização do ECI pelo STF e perceber o diálogo entre a ADPF 347 e o ciclo das políticas públicas.

\section{ARGUMENTOS CENTRAIS DA EMENTA DO ACÓRDÃO}

\subsubsection{Adequação do instrumento para a manutenção da integridade física dos custodiados}

Cabível a arguição de descumprimento de preceito fundamental considerada a situação degradante das penitenciárias no Brasil.

\subsubsection{Configuração do Estado de Coisas Inconstitucional}

Diante do quadro de superlotação carcerária e condições desumanas de custódia no sistema penitenciário nacional, presença de quadro de violação massiva e persistente de direitos 
fundamentais, decorrente de falhas estruturais e falência de políticas públicas e modificação do quadro depende de medidas abrangentes de natureza normativa, administrativa e orçamentária.

\subsubsection{Contingenciamento de verbas do FUNPEN}

O interesse público direciona a liberação das verbas do Fundo Penitenciário Nacional, ante a situação precária das penitenciárias.

\subsubsection{Observância Obrigatória das audiências de custódia}

Obriga os juízes e tribunais a realizarem, em até 90 dias, audiências de custódia, observando os artigos 9.3 do Pacto dos Direitos Civis e Políticos e 7.5 da CIDH. Além de viabilizar o comparecimento do preso perante a autoridade judiciária no prazo máximo de 24 horas, contado do momento da prisão.

\subsubsection{Dispositivo do Acórdão}

Medida cautelar julgada parcialmente procedente, deferindo dois dos oito pedidos, julgando prejudicado um deles e indeferindo os demais. O Supremo, então, determinou que se todos os juízes e tribunais que passem a realizar audiências de custódia, no prazo máximo de 90 dias, aplicando os arts. 9.3 do Pacto dos Direitos Civis e Políticos e 7.5 da Convenção Interamericana de Direitos Humanos; e impôs o imediato descontingenciamento das verbas existentes no Fundo Penitenciário Nacional (FUNPEN), vedando a União a realização de novos contingenciamentos, até que se reconheça a superação do ECI do sistema prisional brasileiro. Além dos argumentos utilizados na ementa pelo Relator, os demais Ministros ao proferir seus votos utilizaram-se de alguns outros, os quais foram agrupados em uma análise comparativa apresentada abaixo, juntamente à deliberação sobre os oito pedidos cautelares.

\subsubsection{Análise comparativa dos argumentos}

\begin{tabular}{|l|l|}
\hline A situação vexaminosa das prisões: ofensa a preceitos fundamentais & Marco \\
& Aurélio; \\
Roberto \\
Barroso; \\
Teori \\
Zavascki; Luiz \\
Fux; Gilmar \\
Mendes; e \\
Celso de Mello \\
\hline Legitimidade da CRFB: ofensa a preceitos fundamentais & Edson Fachin \\
\hline
\end{tabular}




\begin{tabular}{|c|c|}
\hline A responsabilidade do Poder Público & $\begin{array}{l}\text { Marco Aurélio e } \\
\text { Carmen Lúcia }\end{array}$ \\
\hline O papel do STF & $\begin{array}{l}\text { Marco } \\
\text { Aurélio; } \\
\text { Roberto } \\
\text { Barroso; Luiz } \\
\text { Fux; Carmen } \\
\text { Lúcia; Celso de } \\
\text { Mello; } \quad \text { e } \\
\text { Ricardo } \\
\text { Lewandowski }\end{array}$ \\
\hline Necessidade de diálogo com a sociedade & $\begin{array}{l}\text { Roberto } \\
\text { Barroso e } \\
\text { Carmen Lúcia }\end{array}$ \\
\hline Configuração do "estado de coisas inconstitucional" & $\begin{array}{l}\text { Marco } \\
\text { Aurélio; Edson } \\
\text { Fachin } \\
\text { Roberto } \\
\text { Barroso; Teori } \\
\text { Zavascki; Rosa } \\
\text { Weber; Luiz } \\
\text { Fux; Gilmar } \\
\text { Mendes; Celso de } \\
\text { Mello; e Ricardo } \\
\text { Lewandowski }\end{array}$ \\
\hline
\end{tabular}

\begin{tabular}{|l|l|l|l|}
\hline \multirow{2}{*}{} & \multicolumn{2}{|c|}{ Medidas Cautelares } \\
\cline { 2 - 4 } & Defere & Indefere & Prejudicada \\
\hline $\begin{array}{l}\text { a) determinar que todos os juízes e } \\
\text { tribunais que, em cada caso de decretação } \\
\text { ou manutenção de prisão provisória, } \\
\text { motivem expressamente as razões que } \\
\text { impossibilitam a aplicação das medidas }\end{array}$ & Aurélio; Luiz & $\begin{array}{l}\text { Roberto } \\
\text { Barroso; } \\
\text { cautelares alternativas à privação de } \\
\text { liberdade. }\end{array}$ & $\begin{array}{l}\text { Teori } \\
\text { Carmen Lúcia } \\
\text { Roscki; } \\
\text { Rosa Weber; } \\
\text { Gilmar } \\
\text { Mendes; Celso de } \\
\text { Mello; e Edson } \\
\text { Fachin }\end{array}$ \\
\hline
\end{tabular}




\begin{tabular}{|l|l|l|}
\hline b) reconhecer a aplicabilidade imediata & Marco & \\
dos arts. 9.3 do Pacto dos Direitos Civis e & Aurélio; & \\
Políticos e 7.5 da Convenção & Edson Fachin; & \\
Interamericana de Direitos Humanos, & Roberto & \\
determinando a todos os juízes e tribunais & Barroso; Teori & \\
que passem a realizar audiências de & Zavascki; & \\
custódia, no prazo máximo de 90 dias, de & Rosa Weber; & \\
modo a viabilizar o comparecimento do & Luiz Fux; & \\
preso perante a autoridade judiciária em & Lewandowski; & \\
até 24 horas contadas do momento da & Celso de & \\
prisão. & Mello; Carmen & \\
& Lúcia; e & \\
& Gilmar & \\
& Mendes & \\
c) determinar aos juízes e tribunais & Marco & \\
brasileiros que passem a considerar & Aurélio; & Teori \\
fundamentadamente o dramático quadro \\
fático do sistema penitenciário brasileiro \\
no
\end{tabular}

\begin{tabular}{|l|l|l|l|}
\hline $\begin{array}{l}\text { momento de concessão de cautelares } \\
\text { penais, na aplicação da pena e durante o } \\
\text { processo de execução penal. }\end{array}$ & $\begin{array}{l}\text { Carmen Lúcia } \\
\text { Celso de Mello; e } \\
\text { Edson Fachin }\end{array}$ & \\
\hline $\begin{array}{l}\text { d) reconhecer que como a pena é } \\
\text { sistematicamente cumprida em condições } \\
\text { muito mais severas do que as admitidas } \\
\text { pela ordem jurídica, a preservação, na } \\
\text { medida do possível, da proporcionalidade } \\
\text { e humanidade da sanção impõe que os } \\
\text { juízes brasileiros apliquem, sempre que } \\
\text { for viável, penas alternativas à prisão. }\end{array}$ & $\begin{array}{l}\text { Lewandowski; } \\
\text { Carmen Lúcia }\end{array}$ & $\begin{array}{l}\text { Rosa } \\
\text { Resa Weber; } \\
\text { Gilmar } \\
\text { Mendes; } \\
\text { Celso de } \\
\text { Mello; e } \\
\text { Edson Fachin }\end{array}$ & \\
& & & \\
\hline
\end{tabular}




\begin{tabular}{|c|c|c|c|}
\hline $\begin{array}{l}\text { e) afirmar que o juízo da execução penal } \\
\text { tem o poder-dever de abrandar os } \\
\text { requisitos temporais para a fruição de } \\
\text { benefícios e direitos do preso, como a } \\
\text { progressão de regime, o livramento } \\
\text { condicional e a suspensão condicional da } \\
\text { pena, quando se evidenciar que as } \\
\text { condições de efetivo cumprimento da } \\
\text { pena são significativamente mais severas } \\
\text { do que as } 70 \text { previstas na ordem jurídica e } \\
\text { impostas pela sentença condenatória, } \\
\text { visando assim a preservar, na medida do } \\
\text { possível, a proporcionalidade e } \\
\text { humanidade da sanção. }\end{array}$ & $\begin{array}{l}\text { Gilmar } \\
\text { Mendes }\end{array}$ & $\begin{array}{l}\text { Marco } \\
\text { Aurélio; } \\
\text { Roberto } \\
\text { Barroso; } \\
\text { Teori } \\
\text { Zavascki; } \\
\text { Rosa Weber; } \\
\text { Luiz Fux; } \\
\text { Lewandowski; } \\
\text { Celso de } \\
\text { Mello; } \\
\text { Edson Fachin; e } \\
\text { Carmen Lúcia }\end{array}$ & \\
\hline $\begin{array}{l}\text { f) reconhecer que o juízo da execução } \\
\text { penal tem o poder-dever de abater tempo } \\
\text { de prisão da pena a ser cumprida, quando } \\
\text { se evidenciar que as condições de efetivo } \\
\text { cumprimento da pena foram } \\
\text { significativamente mais severas do que as } \\
\text { previstas na ordem jurídica e impostas } \\
\text { pela sentença condenatória, de forma a } \\
\text { preservar, na medida do possível, a } \\
\text { proporcionalidade e humanidade da } \\
\text { sanção. }\end{array}$ & & $\begin{array}{l}\text { Marco } \\
\text { Aurélio; } \\
\text { Roberto } \\
\text { Barroso; } \\
\text { Teori } \\
\text { Zavascki; } \\
\text { Rosa Weber; } \\
\text { Luiz Fux; } \\
\text { Lewandowski; } \\
\text { Celso de } \\
\text { Mello; } \\
\text { Carmen Lúcia; } \\
\text { Edson Fachin; e } \\
\text { Gilmar } \\
\text { Mendes }\end{array}$ & \\
\hline $\begin{array}{l}\text { g) determinar ao CNJ que coordene um ou } \\
\text { mais mutirões }\end{array}$ & Edson Fachin; & & Marco Aurélio; \\
\hline $\begin{array}{l}\text { carcerários, de modo a viabilizar a pronta } \\
\text { revisão de todos os processos de execução } \\
\text { penal em curso no país que envolvam a } \\
\text { aplicação de pena privativa de liberdade, } \\
\text { visando a adequá-los aos pedidos "e" e } \\
\text { "f". }\end{array}$ & $\begin{array}{l}\text { Roberto } \\
\text { Barroso; } \\
\text { Celso de } \\
\text { Mello; e } \\
\text { Gilmar } \\
\text { Mendes }\end{array}$ & & $\begin{array}{l}\text { Luiz Fux; } \\
\text { Lewandowski; } \\
\text { Teori } \\
\text { Zavascki; } \\
\text { Rosa Weber; e } \\
\text { Carmen Lúcia }\end{array}$ \\
\hline
\end{tabular}

e) afirmar que o juízo da execução penal progressão de regime, o livramento condicional e a suspensão condicional da pena, quando se evidenciar que as mpostas visando assim a preservar, na medida do possível, a proporcionalidade e humanidade da sanção. reconhecer que o juízo da execução se evidenciar que as condições de efetivo cumprimento da pena foram significativamente mais severas do que as previstas na ordem jurídica e impostas sanção. 


\begin{tabular}{|l|l|l|l|}
\hline h) impor or imediato & Marco & \\
descontingenciamento das verbas & Aurélio; Luiz & \\
existentes no FUNPEN, e vedar à União & Fux; & \\
$\begin{array}{l}\text { Federal a realização de novos } \\
\text { contingenciamentos, até que se } \\
\text { reconheça a superação do ECI do sistema } \\
\text { prisional brasileiro. }\end{array}$ & $\begin{array}{l}\text { Lewandowski; } \\
\text { Roberto } \\
\text { Barroso }\end{array}$ & & \\
\hline $\begin{array}{l}\text { Concessão de cautelar de ofício para que se determine à União e aos Estados, e especificamente ao } \\
\text { Estado de São Paulo, que encaminhem ao STF informações }\end{array}$ & \\
\hline sobre a situação prisional & \\
\hline $\begin{array}{l}\text { Edson Fachin; Roberto Barroso; Teori Zavascki; Rosa Weber; } \\
\text { Celso de Mello; e Gilmar Mendes }\end{array}$ & $\begin{array}{l}\text { Marco Aurélio; Luiz Fux; } \\
\text { Cármen Lúcia; e } \\
\text { Lewandowski }\end{array}$ \\
\hline
\end{tabular}

O ECI é então encarado na ADPF 347 como um ativismo judicial dialógico, e é declarado no Acórdão. Esse ativismo no ECI não implica uma usurpação judicial dos poderes administrativos ou legislativos, mas favorece a racionalidade no processo decisório, para Marmelstein. Nesse sentido, “a ideia é fazer com que os responsáveis assumam as rédeas de suas atribuições e adotem as medidas, dentro de sua esfera de competência, para solucionar o problema" (MARMELSTEIN, 2015, p.250).

Contudo, diante do julgamento das cautelares pleiteadas, percebesse que quase todas elas (exceto uma que instiga mudança do Executivo) se dirigem ao Judiciário e são em sua quase totalidade contempladas por lei ou já está em curso, o que leva a apreciação de apenas dois dos oito pedidos. Assim, a exordial da ADPF não embasa em seus pedidos o ECI que ela pleiteia que seja declarado. $\mathrm{O}$ que ocorre na verdade é um ataque as consequências do sistema penitenciário brasileiro de maneira inócua e retórica, sem confrontar as causas, que muito instigariam o Legislativo para mudanças. No acórdão, entretanto, os Ministros parecem separar a apreciação das medidas cautelares, julgando-as, da própria declaração do ECI, que fazem a partir da análise o cenário da política pública carcerária do Brasil que afronta princípios e garantias constitucionais cotidianamente.

\section{DIÁLOGO ENTRE A ADPF 347 E O CICLO DAS POLÍTICAS PÚBLICAS}

Analisa-se, então, a influência da incorporação do ECI pela ADPF 347 na efetivação da política pública carcerária, objeto da ação, a partir da classificação do "ciclo das políticas

\footnotetext{
${ }^{1}$ Proposta do Ministro Roberto Barroso.
} 
públicas”. Objetiva-se perceber também em qual etapa desse ciclo se insere a judicialização da política pública carcerária por meio da ADPF 347.

\subsection{Breve introdução ao "policy cycle"}

O processo de elaboração de políticas públicas pode ser enquadrado em um esquema de organização interpretativo e didático, conhecido como ciclo das políticas públicas (policy cycle) ou processo de elaboração de políticas públicas (policy-making process) composto por sete fases sequenciais principais: a identificação do problema, a formação da agenda, a formulação de alternativas, a tomada de decisões, a implementação, a avaliação e a extinção. Esse modelo surgiu entre os séculos XIX e XX em um contexto de busca de racionalização do Estado, na busca por um processo decisório de efetividade.

Essa concepção abstrata do processo político que compõe um ciclo, formado por etapas permite o exame dos elementos do processo político-administrativo quanto aos atores, as relações de poder envolvidas, os recursos empregados, em suma: as redes políticas e sociais e as práticas em cada fase (SECCHI, 2013). Ao longo do ciclo das políticas públicas, diversos atores contribuem para a sua formação, implementação e também avaliação. O papel dos juízes nesse contexto como atores governamentais é o que se busca investigar, percebendo como a tomada de decisões pelo Judiciário influencia na efetivação das políticas públicas (HOWLETT, 2013).

Não obstante a importância didática desse conceito, inclusive para sistematização e compreensão da política, sua a real dinâmica apresenta as fases misturadas e alternadas. Assim, as fases metodológicas ou ilustrativas do passo a passo da formação de uma política pública, na prática, têm múltiplos designs. Cada uma dessas etapas constrói uma peça que compõem a política pública, aqui compreendida como uma "diretriz elaborada para enfrentar um problema público" (SECCHI, 2013, p.2), a partir de um "conjunto de processos que culmina na escolha racional e coletiva de prioridades para a definição dos interesses públicos reconhecidos pelo direito" (BUCCI, 2002, p.264).

O ciclo inicia-se com a identificação do problema público que deve ser resolvido, mitigado ou diminuído com a inserção deste em uma lista de prioridades de atuação do Poder Público ou dos diversos atores como grupos de interesses, que serão responsáveis por colocar o problema na agenda do dia para solução. A percepção do problema nada mais que é que a discrepância entre o status quo e uma situação ideal possível, ou seja, o ser e o dever ser em uma linguagem mais jurídico-normativa ocorre de maneira intersubjetiva (SECCHI, 2013). Na 
delimitação do problema identificam-se as causas, culpados, obstáculos, soluções possíveis e cria-se norteadores para tais soluções. Os atores interessados na resolução do problema, uma vez definido, irão colocá-lo como prioridade.

A chamada formação da agenda consiste em pôr o conjunto de problemas previamente delimitados no centro do debate político. Dada a pluralidade de atores e interesses, entende-se haver múltiplas agendas decorrentes do interesse dos diferentes agentes do policy cycle. $\mathrm{Na}$ tomada de decisões, “o que há em comum entre todas as políticas públicas é o processo político de escolhas de prioridades para o governo". (BUCCI, 1996, p.7). Para Maria Paula Dallari (1996), ainda, a política pública "transcende os instrumentos normativos do plano ou do programa. Há, no entanto, um paralelo evidente entre o processo de formulação da política e a atividade de planejamento" (p.9). Assim, para a autora a importância da aproximação entre o direito administrativo e as políticas públicas consiste no fato de que "o sucesso da política pública, qualquer que seja ela, está relacionado com a qualidade do processo administrativo que precede a sua realização e que a implementa" (p.9).

Uma vez inserida na agenda política ou formal, a política pública ainda está no plano das ideias e necessita da criação de alternativas para que as decisões sejam tomadas em uma próxima etapa. A formulação de alternativas é a etapa em que são estabelecidos objetivos e estratégias e é feito o estudo das potenciais consequências de cada solução. São elaborados “métodos, programas, estratégias ou ações que poderão alcançar os objetivos estabelecidos" (SECCHI, 2013, p.48). Importante destacar que "quanto mais concretos forem os objetivos, mais fácil será verificar a eficácia da política pública” (p.48), observada, sobretudo, na fase posterior da avaliação.

A tomada de decisões "representa o momento em que os interesses e intenções dos atores são equacionados e as diretrizes para o enfrentamento de um problema público são explicitadas" (p.51). Tal dinâmica demonstra que um fluxo de circunstâncias condiciona o processo de formação de uma política pública que quando convergem, formam uma "janela de oportunidade", cuja situação política e econômica é favorável para determinada tomada de decisões. Nessa etapa resta claro que "quando se está diante da necessidade da elaboração de uma política pública é preciso que o agente público demonstre argumentativamente do ponto de vista racional o porquê da escolha que fez para a política pública, com base no que está previsto pela Constituição Federal" (SOARES, 2011, p.80). Nesse corolário, os direitos fundamentais sociais e sua eficácia devem ser base das políticas públicas. 
A implementação, posteriormente, é a fase em que os resultados concretos da política pública passam, então, a ser produzidos, as intenções convertem-se em ações. A importância de estudar essa etapa está em "visualizar os obstáculos e falhas que costumam acometer essa fase" do policy cycle. A etapa que pressupõe a execução das políticas públicas necessita de instrumentos para tanto, isto é, "meios disponíveis para transformar as intenções em ações políticas" (SECCHI, 2013, p.58). A avaliação é um momento de feedback das fases antecedentes e dos resultados gerados pelas políticas públicas. Pode ser anterior, posterior ou in itinere ao processo de implementação, o que corresponde ao monitoramento da política. Ocorre então um exame de todo o desempenho da política pública, "com o intuito de conhecer melhor o nível de redução dos problemas que ela gerou" (SECCHI, 2013, p.63). Os principais critérios a serem utilizados nessa fase são: economicidade; produtividade; eficiência econômica e administrativa; eficácia e equidade.

Além de poder se basear em parâmetros diversos, a análise de uma política pública pode levar a continuação desta da forma como está, a reestruturação marginal de aspectos práticos, ou à sua extinção. A apresentação clara dos resultados é outro elemento relevante que o processo avaliativo deve gerar, uma vez que as informações extraídas devem ser publicizadas. O tempo para maturação: ajustamento e assimilação dos seus propósitos é também importante nessa etapa. As avaliações servem, assim, para superar "debates simplistas e maniqueístas" (SECCHI, 2013, p.66). A extinção é um dos resultados possíveis a uma política pública, tendo como principais causas a resolução do problema que originou a política, percebe-se a ineficácia dos programas ou ações que ativavam a política e a política perdeu a importância, embora o problema não tenha sido resolvido, e saiu da agenda. Há também políticas públicas com prazo determinado, e que, portanto, se extinguem quando há a implementação desta e finaliza seu ciclo (SECCHI, 2013). Importante destacar que esse modelo esquemático do ciclo das políticas públicas é analisado de forma totalmente abstrata ou subjetiva, entretanto uma soma de fatores conduz às diversas etapas em momentos oportunos política e juridicamente.

Ademais, as políticas públicas desenvolvem-se nas instituições. O arranjo institucional comporta uma política compreende "seu marco geral de ação, incluindo uma norma instituidora da qual conste o quadro geral das autoridades competentes, as decisões previstas para concretização das políticas, além do balizamento da conduta dos agentes privados envolvidos" (BUCCI, 2013, p. 238). Tais arranjos, quando padronizados se tornam modelos institucionais. As políticas públicas, no modelo institucionalista “cobram legalidade e, portanto, cumprimento por parte dos responsáveis e atingem todas as pessoas da sociedade, independentemente, do 
grupo que por ventura pertençam" (SOARES, 2011, p.73). Com base nesse modelo justifica-se o controle judicial das políticas públicas.

Em geral, os juízes atuam como atores do ciclo das políticas públicas na etapa de implementação, quando interpretam "a justa ou injusta aplicação de uma lei por parte dos cidadãos e da própria administração pública” (SECCHI, 2013, p.107). Também são protagonistas na elaboração das políticas públicas, quando emitem "decisão judicial que torne pública a interpretação sobre determinada norma legal”. A necessidade de argumentação em consonância com a Constituição é defendida por Soares (2011, p.70) para que o juiz chegue à conclusão em determinado caso sobre políticas públicas, legitimando o controle judicial destas.

Diogo Coutinho e Carlos Aurélio de Faria (2013) defendem a ideia de que o direito permeia intensamente as políticas públicas em todas as suas fases ou ciclos. A aproximação do campo jurídico na formulação e aplicação das políticas públicas é de extrema relevância, o que deveria se refletir na consciência do papel dos profissionais da área jurídica, já que o direito também estrutura e regula formas de prestação de contas e transparência (accountability) dessas políticas - uma vez que pode obrigar quem as opera a justificar e motivar as decisões relativas à definição de prioridades, seleção de meios, formulação de planos de execução, alocação de recursos e outras consideradas de interesse público.

Ademais, Coutinho apresenta o argumento que políticas públicas requerem medidas legislativas e complexas ações administrativas que dependem, em última instância, da combinação de ações políticas e expertise técnica para as quais o Judiciário não é capacitado, nem legitimado para tanto. Soares (2011) também realiza o prognóstico de Coutinho de que os aplicadores do direito agem como se não houvesse um espaço para a política na elaboração de políticas públicas. Assim, após a introdução conceitual e pequenas considerações sobre o polyce cycle, e sobre o diálogo das políticas públicas com o direito, passamos a analisar em qual etapa do ciclo da política carcerária se insere o ajuizamento da ADPF 347, percebendo, assim, o papel que os ministros desempenharam na arguição, enquanto atores da política pública objeto da ação.

\subsection{Inserção da ADPF 347 nas etapas do ciclo da política carcerária}

Qual etapa do ciclo das políticas públicas dialoga com a propositura da ADPF 347? Propôs-se perceber em qual etapa se insere a judicialização da política pública carcerária por meio da ADPF 347. A hipótese da pesquisa, a partir do questionamento acima, foi que a ADPF 347, cujo objeto é a política carcerária brasileira, almejando o "reconhecimento do estado de 
coisas inconstitucional do sistema penitenciário", se insere na etapa do ciclo das políticas públicas conhecida como avaliação. Entretanto, adota-se a ideia que as etapas do ciclo também dialogam entre si, o que possibilita que as diretrizes pleiteadas na ADPF em análise se insiram na fase do policy cycle denominada 'formulação de alternativas'.

A hipótese apresentada seria que a ADPF 347 se insere no ciclo das políticas públicas tanto na fase da avaliação quanto na formulação de alternativas. Tal hipótese parte do pressuposto que a arguição busca a deflagração do insucesso e da inconstitucionalidade em que se apresenta a política criminal e penitenciária, almejando o monitoramento do sistema prisional e a adoção de medidas na própria implementação da política pública nas cadeias brasileiras. Acolhe-se em parte tal hipótese.

A avaliação judicial é vista por Howlett (2013, p.211) como "aquelas que tratam de possíveis conflitos entre ações do governo e os princípios constitucionais", ressalta-se ainda que os fundamentos dessa espécie de avaliação das políticas públicas pelas Cortes “em geral se reportam ao exame da constitucionalidade da política a ser implementada ou à possibilidade de sua implementação ou desenvolvimento terem violado os princípios de direitos naturais e/ou de justiça em sociedades democráticas”. Enquanto a formulação de alternativa é a etapa em que são estabelecidos objetivos e estratégias e é feito o estudo das potenciais consequências de cada solução.

Nesse sentido, Bucci (2013) possui contribuição bastante relevante para a "criação de mecanismos formais ou informais de mediação, por meio de "diálogos institucionais" que permitem o estabelecimento de etapas e meios necessários para a implementação dos direitos e das políticas públicas", que consiste na "processualização" das iniciativas objeto dos processos judiciais (p.199). Tal processo de "judicialização da política” é um fator que por si demonstra a processualidade das políticas públicas (p.192). Os diálogos institucionais que Bucci propõe como alternativas se encaixam nos argumentos utilizados na ADPF 347 da responsabilidade do Poder Público, do papel do STF no exercício do poder contramajoritário pela sua intervenção na política pública carcerária e da necessidade de dialogar com a sociedade civil para modificar a realidade dos presídios.

A avaliação, compreendida como momento de feedback das fases antecedentes e dos resultados gerados pelas políticas públicas parece ser a etapa em que a ADPF 347 se insere na política carcerária. A reestruturação marginal de aspectos práticos é o que se busca ao declarar o "estado de coisas inconstitucional", declarando a falência de toda a conjuntura das prisões no Brasil. Tal monitoramento ocorre in itinere (durante o curso da política) ou mesmo pode ser 
considerado posterior a diversos programas que vem sendo incorporados para melhoras, mas não que não tem produzido resultados.

Outrossim, nessa etapa se reconstrói alternativas, mas não é propriamente a "formulação de alternativas", busca-se na verdade reajustar os problemas encontrados no diagnóstico de diversas pesquisas nos cárceres de todo o país. Por isso divergiu-se em parte dessa hipótese inicialmente levantada. Importante destacar ainda outro fator nesse contexto, qual seja a falta de vontade política dos atores na resolução dos problemas encontrados no sistema carcerário. Feitas as considerações anteriores, passamos a identificar as principais repercussões que a declaração do ECI na ADPF 347 poderá gerar para a política pública carcerária.

\subsection{Repercussões do ECI na ADPF 347 e na efetivação da política pública carcerária}

O "estado de coisas inconstitucional" é considerado na ADPF 347 como um ativismo judicial dialógico, e é declarado no Acórdão diante de uma situação de violação generalizada de direitos fundamentais e da inércia ou incapacidade das autoridades públicas em modificar a situação do sistema carcerário brasileiro. A superação deste estado necessita da atuação de uma pluralidade de órgãos dos três poderes, sendo o Judiciário interventor e coordenador institucional, inclusive com medidas de natureza orçamentária. Em um contexto de crise do Estado social, Campilongo (2002) diagnostica que "o Judiciário ganha uma função especial de guardião da legalidade e da moralidade das eleições e do controle das políticas públicas" (p.109).

Assim, nas palavras de Alexandre Costa, a existência de um controle judicial mais presente sobre a atuação governamental, não se trata de um exercício de voluntarismo por integrantes da magistratura, mas de "um movimento consistente, formalizado pelo Poder Legislativo, cujo sentido claro é evitar a procrastinação das decisões sobre conflitos, sustentando a decidibilidade judicial mais célere e eficaz" (COSTA, 2013, p.194). Nesse sentido, é que se imagina deva caminhar a análise do Acórdão da ADPF 347 e que se enxerga a possibilidade do ECI traz resultados para a política carcerária.

Os pedidos da peça exordial da ADPF 347, portanto, afastaram a possibilidade de maior interferência do Judiciário na política pública carcerária, mais uma vez ajuizada, sendo que em seu aspecto mais amplo e generalizado. A possibilidade de o STF agir de maneira mais interventiva também foi bastante debatida no Acórdão, independentemente dos pedidos, sendo o papel do Supremo, a judicialização da política e o ativismo judicial postos em recorrentes discussões. A declaração do ECI, contudo, não obstante ter sido acompanhada de pedidos 
liminares pouco aplicados nesse momento, poderá servir de plano de fundo para que o julgamento final da ADPF abarque o envolvimento de diálogos e cooperação institucional entre todos os poderes, tal qual o instrumento se propõe em sua origem na Corte Colombiana. A decisão, assim, poderá gerar prestações mais positivas e alterações institucionais para mudanças no sistema penitenciário em fase de avaliação, o que contribuirá para a minoração de alguns problemas recorrentes evidenciados no panorama caótico atual das prisões brasileiras e ampliará a efetivação dessa política.

\section{CONCLUSÃO}

Diante da pesquisa e das considerações até aqui apresentadas neste trabalho nota-se que a realidade do sistema carcerário brasileiro apresentou pouquíssimas mudanças desde 1999 até 2015, quando a ADPF 347 foi proposta. Na ação postulou-se, em síntese, que a Corte reconhecesse e declarasse o estado de coisas inconstitucional do sistema prisional brasileiro e, diante disso, impusesse a adoção de uma série de medidas voltadas à promoção da melhoria das condições carcerárias do país, a contenção e reversão do processo de hiperencarceramento que o Brasil vivencia.

A ADPF desafia, portanto, a intervenção da jurisdição constitucional brasileira, não apenas aspectos do controle, mas outras ações ou omissões do poder público. Pugna-se pela proteção à dignidade de grupos vulneráveis, em um exercício do papel contramajoritário do STF. Ante o pedido em caráter liminar incorporou-se na Suprema Corte brasileira o instrumento colombiano denominado "estado de coisas inconstitucional”. Este mecanismo se volta ao enfrentamento de violações graves e sistemáticas da Constituição, decorrentes de falhas estruturais em políticas públicas, cuja superação demanda providências variadas de diversas autoridades e poderes estatais

A situação vexaminosa das prisões como ofensa a preceitos fundamentais, a responsabilidade do Poder Público, em especial o papel do Supremo, diante desse quadro de violações massivas no sistema carcerária e a importância do diálogo com a sociedade para solucionar esse conjunto de problemas detectados, sintetizam a argumentação apreciação diante da política carcerária do país, objeto da ação, utilizada pelos Ministros na apreciação dos pedidos cautelares da ADPF 347. Fundamentos esses que além da declaração do ECI, levaram ao deferimento deferindo os pedidos " $b$ " e " $h$ ", que determinar que os juízes e tribunais realizem, em até 90 dias, audiências de custódia, conforme o último argumento acima 
apresentado. E que a União que libere o saldo acumulado do FUNPEN para utilização com a finalidade para a qual foi criado, abstendo-se de realizar novos contingenciamentos.

O ECI é então encarado na ADPF 347 como um ativismo judicial dialógico, e é declarado no Acórdão. Contudo, diante do julgamento das cautelares pleiteadas, percebesse que quase todas elas (exceto uma que instiga mudança do Executivo) se dirigem ao Judiciário e são em sua quase totalidade contempladas por lei ou já estão em curso, o que leva a apreciação de apenas dois dos oito pedidos. Assim, a exordial da ADPF não embasa em seus pedidos o estado de coisas inconstitucional que ela pleiteia que seja declarado. O que ocorre na verdade é um ataque as consequências do sistema penitenciário brasileiro de maneira inócua e retórica, sem confrontar as causas, que muito instigariam o Legislativo para mudanças.

Tal decisão colegiada, como se depreende, tem natureza declaratória e poderá ser utilizada como precedente para que o STF declare o ECI diante de outras situações fáticas nacionais em que se constate violações constitucionais massivas em grande escala, a exemplo do SUS e de toda aparelhagem das políticas de saúde pública; das chacinas que ocorrem nas favelas e nos bairros suburbanos em confronto com a polícia; do tráfico de drogas e do mercado dele decorrente; da tentativa de criminalização dos movimentos sociais; além de outras hipóteses que se vislumbre. Resta, porém, necessário que os pedidos se utilizando do ECI contemplem soluções que envolvam diálogos e cooperação institucional, entre todos os poderes tal qual o instrumento se propõe em sua origem na Corte Colombiana, para que não se torne mero argumento retórico e inócuo.

Ademais, a ADPF 347, cujo objeto é a política carcerária brasileira se insere na etapa do ciclo das políticas públicas da "avaliação", compreendida como momento de feedback das fases antecedentes e dos resultados gerados pelas políticas públicas, em que ocorre um exame de todo o seu desempenho. Tal monitoramento ocorre in itinere (durante o curso da política) ou mesmo pode ser considerado posterior a diversos programas que vem sendo incorporados para melhoras, mas não que não tem produzido resultados. Nessa etapa reconstroem-se alternativas, mas não é propriamente a fase do ciclo de políticas públicas intitulada "formulação de alternativas". Busca-se, na verdade, reajustar os problemas encontrados no diagnóstico de diversas pesquisas nos cárceres de todo o país.

A decisão, assim, pode gerar prestações mais positivas e alterações institucionais para mudanças no sistema penitenciário em fase de avaliação, o que contribuirá para a minoração de alguns problemas recorrentes evidenciados no panorama caótico atual das prisões brasileiras e ampliará a efetivação dessa política. Acrescente-se, ainda, que conforme os documentos 
apresentados no capítulo dois deste trabalho, a construção de inúmeras novas celas e estabelecimentos prisionais não é a solução mais adequada para se repensar a cadeia. Estudiosos de criminologia recorrentemente demonstram em suas pesquisas, tais quais as explanadas na primeira parte do trabalho, soluções alternativas ao encarceramento. Não se pretendeu com essa pesquisa fazer proposições nesse sentido, mas realizou-se o estudo de caso da ADPF 347 e a partir dele objetivou-se demonstrar como a declaração do ECI no Acórdão pode agir na mudança desse contexto.

\section{REFERÊNCIAS}

ARIZA, L. J. The Economic and Social Rights of Prisioners and Constitutional Court Intervention in the Penitenciary System in Colombia. In: BONILLA, D. M.

Constitutionalism of the Global South. Cambridge: Cambridge University Press, 2013.

ADORNO, S. Sistema penitenciário no Brasil-Problemas e desafios. Revista Usp, n. 9, p. 6578, 1991.

BRASIL. Congresso Nacional. Câmara dos Deputados. Comissão Parlamentar de Inquérito do Sistema Carcerário. CPI sistema carcerário. - Brasília: Câmara dos Deputados, Edições Câmara, 2009. 620 p. Disponível em:

<http://bd.camara.gov.br/bd/handle/bdcamara/2701> Acesso em: 23 ago.2016.

Ministério da Justiça. Conselho Nacional de Política Criminal e

Penitenciária. Plano Nacional de Política Criminal e Penitenciária. Aprovado na $372^{\text {a }}$ reunião ordinária, 2011.

. Supremo Tribunal Federal. Petição Inicial da Arguição de Descumprimento de

Preceito Fundamental $n^{o}$ 347. Disponível

em: <http://redir.stf.jus.br/estfvisualizadorpub/jsp/consultarprocessoeletronico/Consultar ProcessoEletronico.jsf?seqobjetoincidente=4783560> . Acesso em: 04 jun. 2016.

Disponível

em: $\langle$ http://www.stf.jus.br/portal/processo/verProcessoAndamento.asp?incidente $=47835$ 60>

Acesso em: 07 jun. 2016.

BUCCI, M.P.D. Políticas Públicas e Direito Administrativo. Revista de informação legislativa, v. 34, n. 133, p. 89-98, jan./mar. 1997.

. Direito Administrativo e Políticas Públicas. São Paulo: Saraiva, 2002.

. Fundamentos para uma teoria jurídica das políticas públicas. São Paulo:

Saraiva, 2013.

ADPF 347. Relator: Ministro Marco Aurélio. DJe. 20.08.2015. 
CAMPILONGO, C. F. Política, sistema jurídico e decisão judicial. 2.ed. São Paulo: Max Limonad, 2002.

CAMPOS, C. A. A. Da Inconstitucionalidade por Omissão ao Estado de Coisas Inconstitucional. UERJ. Tese de Doutorado em Direito Público, 2015.

CIDH. Informe sobre los derechos humanos de las personas privadas de libertad en las Américas / Comisión Interamericana de Derechos Humanos. v. II; cm. (OEA documentos oficiales ; OEA/Ser.L. Doc.64), 2011 ISBN 978- 0- 8270- 5743- 2. Disponível em: <http://www.oas.org/es/cidh/ppl/docs/pdf/ppl2011esp.pdf>. Acesso em: 23 ago.2016.

COHEN, M.D.; MARCH, J.G.; OLSEN, J.P. A Garbage can model of organizational choice. Administrative Science Quarterly. v.17 n.1, p.1-25, 1972.

COLOMBIA. Corte Constitucional. Sentencia T-025 de 2004. Disponível em: <http://www.corteconstitucional.gov.co/relatoria/2004/t-025-04.htm>. Acesso em: 30 ago 2016.

COSTA, A. A. Judiciário e interpretação: entre direito e política. Revista Pensar, v. 18, n. 1, p. 9-46, 2013.

CNMP. A visão do Ministério Público brasileiro sobre o sistema prisional brasileiro / Conselho Nacional do Ministério Público. - Brasília: CNMP, 2013. 320 p. il.

FARIA, C. A. P.; COUTINHO, D. R. O Direito nas Políticas Públicas. In: MARQUES, E; DE FARIA, C.A.P. (org.). A Política Pública como Campo Multidisciplinar. 1 ed. São Paulo: Editora Unesp e Rio de Janeiro: Editora Fiocruz, 2013, v. 1, p. 181-200.

GRAVITO, C. R.; FRANCO, D. R. Cortes y Cambio Social. Cómo la Corte Constitucional transformó el desplazamiento forzado en Colombia. Bogotá: Dejusticia, 2010.

HOWLETT, M.; RAMESH, M.; PERL, A. Políticas públicas: seus ciclos e subsistemas. Uma abordagem integradora. Rio de Janeiro: Elsevier, 2013.

HUAROTO, B. M. R. Estado de Cosas Inconstitucional'y sus Posibilidades como Herramienta para el Litigio Estratégico de Derecho Público. Una Mirada en la Jurisprudencia Colombiana y Peruana. Dissertação de Mestrado em Direito Constitucional. Pontifícia Universidade Católica do Peru, 2013.

MARMELSTEIN, G. Estado das Coisas Inconstitucional: uma análise panorâmica. In.: OLIVEIRA, P.A. (org.); LEAL, G.P. (org.). Diálogos Jurídicos Luso-Brasileiros. Perspectivas atuais de Direito Público: o Direito em tempos de crise. Salvador: 2015, p.241264.

MINAYO, M. C. S (org.). Pesquisa social: teoria, método e criatividade. 26. ed. Petrópolis, RJ: Vozes, 2007. 
SARAVIA, J; RODRÍGUEZ, A. Los desplazados forzados internos en el estado de cosas inconstitucional, un asunto pendiente. Bogotá: Revista Prolegómenos. Derechos y Valores, v.18, n. 35, 2015, p.121-134.

SECCHI, L. Políticas Públicas: conceitos, esquemas de análise e casos práticos. 2.ed. São Paulo: Cengage Learning, 2013.

SOARES, H.C. O Controle Judicial de Políticas Públicas no Brasil: a decisão judicial e sua fundamentação. Revista da Procuradoria Geral do Estado do Rio Grande do Sul, v. 32, 2011, p. 69-93. 